D.O.I.: $10.3895 /$ S1808-04482009000200003

\title{
O NOVO QUALIS: PERSPECTIVAS PARA A PÓS-GRADUAÇÃO EM ENGENHARIA DE PRODUÇÃO
}

\section{THE NEW QUALIS: PERSPECTIVES FOR THE GRADUATION IN PRODUCTION ENGINEERING}

\author{
Bruno Pedroso $^{1}$; Luiz Alberto Pilatti ${ }^{2}$ \\ ${ }^{1}$ Universidade Tecnológica Federal do Paraná - UTFPR - Ponta Grossa - Brasil; Bolsista da \\ Coordenação de Aperfeiçoamento de Pessoal de Nível Superior - CAPES \\ brunops3@brturbo.com.br \\ ${ }^{2}$ Universidade Tecnológica Federal do Paraná - UTFPR - Ponta Grossa - Brasil \\ lapilatti@utfpr.edu.br
}

\begin{abstract}
Resumo
O presente estudo tem como objetivo analisar os efeitos do Qualis referente ao triênio 2007-2009 na aferição da qualidade da produção bibliográfica dos programas de pós-graduação da sub-área Engenharia de Produção. Para tanto, através do levantamento de dados da avaliação trienal de 2004-2006 da CAPES e das informações dos Qualis 2004-2006 e 2007-2009, realizou-se uma analogia entre ambos os Qualis, inferindo as principais alterações que passam a vigorar a partir de então. Foi constatado que a proposta de unificação do Qualis na grande área Engenharias, anunciada pela CAPES, não foi concretizada. Frente à classificação publicada pela CAPES, cujos critérios permanecem implícitos, foi ocasionado o aumento do número de periódicos indexados ao Qualis; apesar do acréscimo de periódicos, os adicionais se concentram nos extratos inferiores do Qualis; as exigência para classificação nos dois extratos superiores do Qualis foram aumentadas; os periódicos editados no Brasil sofreram depreciação e; a sub-área Engenharia de Produção teve uma drástica redução do número de periódicos classificados no extrato superior do Qualis. Conclui-se que o defronte dos programas de pós-graduação em Engenharia de Produção ante a nova classificação do Qualis fomenta um triênio bastante desafiador à sub-área em exame.
\end{abstract}

Palavras-chave: Qualis, Engenharia de Produção, periódicos, produção bibliográfica, pósgraduação.

\section{Introdução}

Falar de pesquisa e pós-graduação no Brasil não é uma empreitada simples. $\mathrm{O}$ ambiente acadêmico sistematicamente vem ganhando em sofisticação e complexidade. Novos elementos e indicadores passaram a compor o cenário, alguns destes advindos do sistema de pós-graduação, os quais vêm redesenhando o ensino, em diferentes níveis, de todas as áreas acadêmicas. Um dos 
elementos mais significativo é o sistema Qualis, que serve para aferir a qualidade da produção bibliográfica dos programas de pós-graduação brasileiros.

O parâmetro empregado é o da conformidade dos veículos ou meios de divulgação utilizados pelos pesquisadores para tornarem públicos os resultados de suas pesquisas. $\mathrm{O}$ sistema implantado em 1998, na sua curta existência, teve sua versão inicial ajustada diversas vezes para minimizar distorções que se apresentaram. O último ajuste foi divulgado pela Coordenação de Aperfeiçoamento de Pessoal de Nível Superior (CAPES), entidade responsável pela avaliação dos programas de pós-graduação brasileiros, em dezembro de 2008, com a apresentação do Qualis relativo aos dados do ano de 2007. Em termos práticos, o sistema Qualis determinou uma acentuada valoração de um número restrito de periódicos consolidados provenientes de áreas de maior tradição acadêmica. O quadro projeta uma direção que não apresenta indicativos de mudanças.

O desnível existente entre grandes áreas com inserção internacional, como é o caso das Ciências Agrárias, e outras ainda frágeis na perspectiva dos cientistas da área verem seus trabalhos publicados serem citados por outros pesquisadores em revistas internacionais, perceptível de forma mais nítida nas Ciências Sociais Aplicadas, é abissal.

A Engenharia de Produção foi, dentro do cenário tracejado, a área escolhida como objeto no presente estudo. Trata-se de uma sub-área com tradição acadêmica restrita e portadora de problemas históricos como autonomia limitada de temas e métodos em relação às engenharias mais tradicionais que compõe a grande área das Engenharias, que está alocada pela CAPES dentro da área das Engenharias III. O objetivo do presente estudo é analisar os efeitos do Qualis, referente às publicações do ano-base 2007, na aferição da qualidade da produção bibliográfica dos programas de pós-graduação da sub-área Engenharia de Produção. O pano de fundo das discussões é a política da CAPES relativa à pós-graduação brasileira.

\section{Avaliação da pós-graduação no Brasil}

A avaliação dos cursos de pós-graduação stricto sensu no Brasil é realizada pela CAPES. São reconhecidos os cursos cujo conceito obtido na avaliação seja igual ou superior a 3 , em uma escala de 1 a 7 . Os cursos reconhecidos atendem aos requisitos estabelecidos pela legislação vigente do Ministério da Educação (MEC) e do Conselho Nacional da Educação (CNE). Estes cursos possuem autorização para expedir diplomas com validade em todo o território nacional (CAPES, 2008).

Os cursos de pós-graduação stricto sensu são divididos em nove grandes-áreas do conhecimento: Ciências Agrárias, Ciências Biológicas, Ciências da Saúde, Ciências Exatas e da Terra, Ciências Humanas, Ciências Sociais Aplicadas, Engenharias, Lingüística/Letras e Artes e 
Multidisciplinar. Cada grande área é seccionada em um número variado de áreas de avaliação, conforme pode ser verificado no quadro 1 :

Quadro 1 - Grandes áreas e suas respectivas áreas de avaliação

\begin{tabular}{|c|c|}
\hline \multirow{4}{*}{ CIÊNCIAS AGRÁRIAS } & Ciências Agrárias \\
\hline & Ciências de Alimentos \\
\hline & Medicina Veterinária \\
\hline & Zootecnia/Recursos Pesqueiros \\
\hline \multirow{4}{*}{ CIÊNCIAS BIOLÓGICAS } & Ciências Biológicas I \\
\hline & Ciências Biológicas II \\
\hline & Ciências Biológicas III \\
\hline & Ecologia e Meio-Ambiente \\
\hline \multirow{9}{*}{ CIÊNCIAS DA SAÚDE } & Educação Física \\
\hline & Enfermagem \\
\hline & Farmácia \\
\hline & Medicina I \\
\hline & Medicina II \\
\hline & Medicina III \\
\hline & Medicina IV \\
\hline & Odontologia \\
\hline & Saúde Coletiva \\
\hline \multirow{5}{*}{ CIÊNCIAS EXATAS E DA TERRA } & Astronomia/Física \\
\hline & Ciência da Computação \\
\hline & Geociências \\
\hline & Matemática/Probabilidade e Estatística \\
\hline & Química \\
\hline \multirow{8}{*}{ CIÊNCIAS HUMANAS } & Antropologia/Arqueologia \\
\hline & Ciência Política e Relações Internacionais \\
\hline & Educação \\
\hline & Filosofia/Teologia \\
\hline & Geografia \\
\hline & História \\
\hline & Psicologia \\
\hline & Sociologia \\
\hline \multirow{7}{*}{ CIÊNCIAS SOCIAIS APLICADAS } & Administração, Ciências Contábeis e Turismo \\
\hline & Arquitetura e Urbanismo \\
\hline & Ciências Sociais Aplicadas I \\
\hline & Direito \\
\hline & Economia \\
\hline & Planejamento Urbano e Regional/Demografia \\
\hline & Serviço Social \\
\hline \multirow{4}{*}{ ENGENHARIAS } & Engenharias I \\
\hline & Engenharias II \\
\hline & Engenharias III \\
\hline & Engenharias IV \\
\hline \multirow{2}{*}{ LINGÜÍSTICA, LETRAS E ARTES } & Artes/Música \\
\hline & Letras/Lingüística \\
\hline \multirow{4}{*}{ MULTIDISCIPLINAR } & Biotecnologia \\
\hline & Ensino de Ciências e Matemática \\
\hline & Interdisciplinar \\
\hline & Materiais \\
\hline
\end{tabular}

Fonte: CAPES (2008) 
Uma área de avaliação, por sua vez, agrupa os programas de pós-graduação que possuem relação com tal área. Assim, uma área de avaliação pode possuir ramificações, denominadas subáreas. O presente estudo possui enfoque na área de avaliação Engenharias III, sobretudo, na subárea Engenharia de Produção. A grande área Engenharias possui quatro áreas de avaliação, cujas respectivas sub-áreas são:

Quadro 2 - Áreas de avaliação e sub-áreas da grande área Engenharias

\begin{tabular}{|c|l|}
\hline ÁREA DE AVALIAÇÃO & \multicolumn{1}{c|}{ SUB-ÁREA } \\
\hline \multirow{4}{*}{ Engenharias I } & Engenharia Civil \\
\cline { 2 - 3 } & Engenharia de Transportes \\
\cline { 2 - 3 } Engenharias II & Engenharia Sanitária \\
\hline \multirow{4}{*}{ Engenharias III } & Engenharia de Materiais e Metalúrgica \\
\cline { 2 - 2 } & Engenharia de Minas \\
\cline { 2 - 2 } & Engenharia Nuclear \\
\cline { 2 - 2 } & Engenharia Química \\
\hline & Engenharia Aeroespacial \\
\cline { 2 - 2 } & Engenharia de Produção \\
\cline { 2 - 2 } & Engenharia Mecânica \\
\cline { 2 - 2 } & Engenharia Naval e Oceânica \\
\hline \multirow{4}{*}{ Engenharias IV } & Engenharia Biomédica \\
\cline { 2 - 2 } & Engenharia Elétrica \\
\hline
\end{tabular}

Fonte: Sampaio e Souza (2008)

Ainda que a avaliação dos cursos de pós-graduação stricto sensu sofra variações em cada área, os indicadores utilizados para tal são os mesmos (proposta do programa, corpo docente, corpo discente/teses e dissertações, produção intelectual, inserção social).

A produção intelectual é o fator mais valorado na avaliação da pós-graduação. Para a avaliação da qualidade da produção intelectual, a CAPES utiliza o Qualis. O sistema Qualis foi implantado em 1998, e, até 2007 (ano-base 2006), classifica a produção intelectual da pósgraduação stricto sensu, quanto ao âmbito de sua circulação (Local, Nacional, Internacional) e com relação ao quesito qualidade (A, B, C), em cada uma das áreas de avaliação (CAPES, 2008). De acordo com a CAPES, o Qualis é:

[...] o conjunto de procedimentos utilizados pela Capes para diferenciação da qualidade da produção bibliográfica dos programas de pós-graduação. A estratificação da qualidade dessa produção é realizada de forma indireta, pela classificação dos veículos utilizados na sua divulgação. Dessa forma, o Qualis afere a qualidade dos artigos e de outros tipos de produção, a partir da análise da qualidade dos periódicos científicos, jornais, eventos, livros etc. (CAPES, 2007a, p. 01)

Com efeito, a combinação de ambas as classificações possibilita nove variações: A Internacional, B Internacional, C Internacional, A Nacional, B Nacional, C Nacional, A Local, B Local e C Local.

As principais características do Qualis, de acordo com a CAPES (2007b, p. 01), são: 
- Atende aos objetivos específicos e exclusivos do processo de avaliação da pós-graduação promovido pela Capes e é basicamente alimentado pelas informações anualmente fornecidas anualmente pelos programas por intermédio do Coleta de Dados;

- Permite a classificação de periódicos e anais utilizados para a divulgação da Produção Intelectual dos programas de pós-graduação stricto sensu, seguindo uma escala de dupla entrada relativa ao âmbito de circulação (internacional, nacional e local) e à sua qualidade (A-alta, B-média e C-baixa);

- É alimentado pelas informações anualmente fornecidas pelos programas de pós-graduação stricto sensu, através do aplicativo Coleta de Dados da Capes e por indicações dos Representantes das Áreas;

- A classificação é feita por Área de Avaliação através de um aplicativo externo ao Sistema de Coleta de Dados, o WebQualis, podendo assim um mesmo veículo ter, para diferentes áreas, diferentes classificações;

- O trabalho realizado pela área é baseado em seus critérios, previamente definidos, respeitando as diretrizes e orientações gerais estabelecidas pelo Conselho Técnico Científico $-\mathrm{CTC}$

- Anualmente acontece a atualização com a inclusão de novos veículos e a reclassificação dos veículos anteriormente classificados;

- As áreas podem classificar revistas típicas de outras áreas, para fins de avaliação da produção (geração dos Cadernos de Avaliação) não sendo necessário indicá-las para publicação no Qualis da área. A transparência do processo de avaliação não é prejudicada tendo em vista que, no Caderno de Indicadores da Produção Intelectual, o programa ou o pesquisador específico poderá identificar a qualificação de sua produção.

Para a avaliação dos programas de pós-graduação stricto sensu no triênio 2007-2009, a CAPES reestruturou o Qualis. Ao contrário da classificação pioneira, os veículos de comunicação são agora classificados a partir de uma única classificação, fusionando as secções quanto ao âmbito e qualidade em uma única classificação. A nova classificação é passível de oito resultados: A1, A2, B1, B2, B3, B4, B5 e C. Dessa forma, os periódicos com melhor e pior avaliação são classificados como A1 e B5, respectivamente. Os periódicos não indexados no Qualis recebem a classificação C.

A CAPES ainda recomenda que "nas grandes áreas em que for possível e, em especial, naquelas em que já é tradição, como as Engenharias e a Saúde, que se mantenha a política de um Qualis único ou de regras únicas para o Qualis" (TOURINHO; BASTOS, 2008, p. 08). Durante a divulgação das mudanças, feitas pelos coordenadores das sub-áreas para os coordenadores de programas de pós-graduação, durante o ano de 2008, aventou-se que tal recomendação seria seguida pela grande área Engenharias. Em termos práticos, as áreas de avaliação Engenharias I, II, III e IV 
deixaram de existir, sendo o Qualis das sub-áreas unificado no Qualis da área Engenharia. Com a publicação do Qualis 2007 verificou-se que o perspectivado não havia se materializado.

Outra importante divulgação feita durante 2008, apesar de nitidamente fora do tempo apropriado, foi a dos critérios para a classificação dos periódicos da grande área Engenharias no triênio 2007-2009. Tratava-se de um avanço fundamental. A comunidade acadêmica passaria a dispor de critérios objetivos para, de forma congruente com um Qualis mais perene, identificar a qualidade do veículo onde estava submetendo sua produção intelectual. A falta deste tipo de regra produziu um cenário volubilíssimo, considerando que os periódicos mais conceituados normalmente apresentam um tempo de publicação longo após a submissão e, com freqüência, uma porção significativa de periódicos sofriam avaliações discrepantes em períodos subseqüentes. Os critérios anunciados para a composição do novo Qualis estão explicitados no quadro 3:

Quadro 3 - Qualis vigente (triênio 2007-2009) da grande área Engenharias

\begin{tabular}{|c|c|c|}
\hline & ENGENHARIA É ÁREA MADRINHA & ENGENHARIA NÃO É ÁREA MADRINHA \\
\hline A1 & $(15 \%)-\quad$ F.I. $>0,9$ & $(4 \%)-j^{*}>1,22$ \\
\hline A2 & $(7 \%)-\quad$ F.I. $<0,9$ e F.I. $>0,5$ & $(4 \%) \quad-\quad j^{*}>1,06$ e $j^{*}<1,22$ \\
\hline B1 & $(4 \%) \quad-\quad$ F.I. $>0,3$ e F.I. $<0,5$ & $(7 \%)-j^{*}>0,8 \mathrm{ej}^{*}<1,06$ \\
\hline B2 & $(2 \%)-$ F.I. $<0,3$ e F.I. $>0 /$ Scielo & $(6 \%)-j^{*}<0,8$ e j$^{*}>0 /$ Scielo \\
\hline B3 & Periódicos de Associações e/ou Q > 6 & Periódicos de Associações e/ou Q > 6 \\
\hline B4 & Sem F.I. e $Q>3$ e $Q<6$ & Sem F.I. e $\mathrm{Q}>3$ e $\mathrm{Q}<6$ \\
\hline B5 & Sem F.I. e $\mathrm{Q}<3$, Local & Sem F.I. e $\mathrm{Q}<3$, Local \\
\hline
\end{tabular}

Fonte: Sampaio e Souza (2008)

Frente a essa nova classificação, todas as sub-áreas ramificadas da grande área Engenharias, apresentadas no quadro 2, mesmo não possuindo um único Qualis, passaram a ter regras menos mutáveis na dimensão mais valorada da avaliação dos programas. Algo absolutamente desejável.

\section{Metodologia}

Para a realização do presente estudo foram levantados dados do triênio 2004-2006 de avaliação dos cursos de pós-graduação stricto sensu, realizada pela CAPES. O número de periódicos de cada área de avaliação da grande área Engenharias foi contabilizado e seccionado de acordo com os extratos de avaliação do Qualis do triênio vigente na ocasião.

Para fins de comparação foram utilizados, dos dados levantados do Qualis do triênio 20042006, somente o número de periódicos A Internacional de cada área de avaliação. Frente ao número de periódicos A Internacional de cada área de avaliação, buscou-se contabilizar o total de artigos publicados em periódicos classificados como tal, em cada uma das sub-áreas da grande área Engenharias. 
Considerando que o número de programas de pós-graduação é variável, o total de artigos publicados se torna um indicador não passível de comparação. Para reverter esse cenário, utilizouse de um indicador proposto no presente trabalho, a "média de artigos" publicados em periódicos A Internacional. Tal indicador consiste na razão entre o total de artigos A Internacional publicados de cada sub-área e o número de programas de pós-graduação da mesma sub-área.

Para efeitos de comparação, utilizou-se de outros dois indicadores, também propostos nesse trabalho, o "percentual de doutorados" e o "conceito médio". O percentual de doutorados é um indicador que varia de 0 a 1 , onde o valor 0 representa que nenhum programa de pós-graduação da sub-área possui doutorado, enquanto o indicador 1 representa que todos os programas de pósgraduação da sub-área possuem doutorado. Já o indicador conceito médio varia de 3 a 7 , sendo representado pela somatória dos conceitos de todos os programas de pós-graduação de determinada sub-área dividido pelo número de programas de pós-graduação de tal área.

De forma adicional, o Qualis referente às publicações do ano-base 2007 da área Engenharias foi interpretado e transcrito textualmente. Foi realizado, também, um comparativo qualitativo entre as classificações do Qualis 2004-2006 e 2007-2009. A partir da comparação entre ambas as classificações, foram destacadas as principais alterações da área de avaliação Engenharias III, enfatizando a sub-área Engenharia de Produção.

\section{Resultados e discussão}

Os indicadores e critérios utilizados para a classificação proposta para o Qualis 2007-2009 foram transcritos textualmente. Interpretando o quadro 3, obtém-se os seguintes critérios para a classificação dos periódicos da área em exame:

- Os periódicos de qualquer área que possuem fator de impacto (F.I.) serão enquadrados como A1, A2, B1 e B2 (quanto maior o fator de impacto, melhor a classificação);

- Nos periódicos de qualquer sub-área da grande área Engenharias, a classificação será realizada a partir do fator de impacto do periódico. Acima de 0,9 corresponde a A1, entre 0,5 e 0,9 a A2, entre 0,3 e 0,5 a B1 e entre 0,01 e 0,3 a B2;

- Nos periódicos de outras áreas, a classificação será realizada a partir do indicador $\mathrm{j}^{*}$, calculado a partir da raiz quadrada do fator de impacto do periódico dividido pelo fator de impacto mediano da área do conhecimento em que o periódico se insere. Os periódicos de outras áreas que possuem $\mathrm{j}^{*}$ maior do que 1,22 são A1, entre 1,06 e 1,22 são A2, entre 0,8 e 1,06 são B1 e entre 0,01 e 0,8 são B2;

- A utilização do indicador $\mathrm{j}^{*}$ ocasiona, de início, a falsa impressão de que periódicos de outras áreas precisam ter fator de impacto maior do que 0,9 (fator de impacto mínimo para 
os periódicos das Engenharias serem classificados como A1) para serem classificados como A1. Essa condição é verdadeira somente se o fator de impacto mediano da área que o periódico se insere, for superior a 0,6. Por exemplo, para que os periódicos da área História (fator de impacto mediano igual à 0,340 ) sejam classificados como $\mathrm{A} 1$, basta que estes possuam fator de impacto igual ou superior a 0,51. Em contrapartida, periódicos da área Biotecnologia (fator de impacto mediano igual a 1,937) serão classificados como A1 somente se o seu fator de impacto for igual ou superior a 1,24;

- Periódicos de circulação internacional, sem fator de impacto, mas importantes para as áreas serão classificados como B1, B2 ou B3, em função do seu grau compatível de citações;

- Cada área de avaliação pode ter até dois periódicos indexados no Scielo classificados como B1. Como são quatro áreas de avaliação da Engenharias (Engenharias I, Engenharias II, Engenharias III e Engenharias IV), haverá oito periódicos nacionais classificados como B1;

- Os demais periódicos indexados no Scielo serão B2;

- Os periódicos sem fator de impacto e não indexados no Scielo de qualquer área, serão classificados como B3, B4 ou B5 em função do fator Q. O fator Q é um índice atribuído em função da qualidade da produção de cada área do conhecimento. Periódicos cujo fator Q é superior a 6,0 são B3, com fator Q entre 3,0 e 6,0 são B4 e com fator Q inferior a 3 são B5. Por exemplo, um periódico classificado como A Nacional na Biologia III possui $Q=5,0$, o que resultaria em uma classificação B4 na Engenharias;

- Aos periódicos da área da Engenharia, que não possuem fator de impacto e não são indexados no Scielo, mas que constavam na classificação do Qualis 2004-2006, terão a seguinte classificação: A Internacional será classificado como B1, B Internacional como B2, C internacional como B3, A nacional como B4 e B Nacional, C Nacional e A Local como B5. Praticamente todos os periódicos classificados no Qualis do triênio 2004-2006 como A Internacional, B Internacional, C Internacional e A Nacional possuem fator de impacto ou estão indexados no Scielo. Dessa forma, esse item é aplicável, em sua maioria, aos periódicos classificados anteriormente como B Nacional, C Nacional e A Local. Apesar de haver um decréscimo significativo na qualidade dos periódicos anteriormente classificados como A Internacional, B Internacional, C Internacional e A Nacional, poucos periódicos com essas classificações se enquadram nesse item;

- Os periódicos de circulação local, de qualquer área do conhecimento, são classificados como B5.

Foi anunciado, também, que o peso dos periódicos para a pontuação dos docentes no quesito produção bibliográfica para avaliação dos programas de pós-graduação no triênio 2007-2009 será o seguinte: 


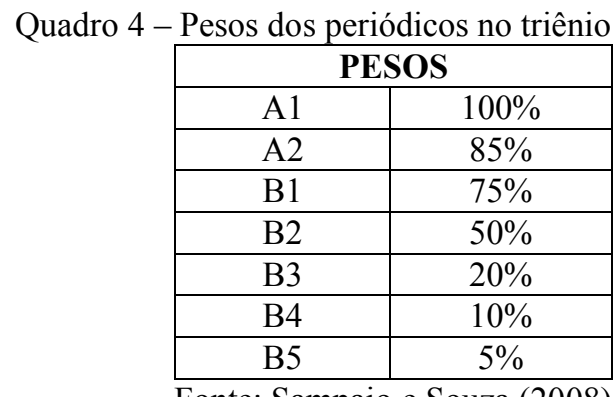

Fonte: Sampaio e Souza (2008)

De forma adicional, fora especificado que haverá saturação para os periódicos B2, B3, B4 e B5. Entretanto, mesmo com o triênio em curso praticamente findado, ainda não foi explicitado qual é a saturação para cada um dos estratos mencionados. Tendo em vista que uma vasta quantidade de novos periódicos foi adicionada e que alguns periódicos foram "reclassificados", não é possível comparar diretamente o Qualis 2004-2006 e 2007-2009. É possível inferir uma equivalência entre ambos, de forma a equiparar os pesos de cada classificação do Qualis 2004-2006 com o Qualis 2007-2009. Essa equivalência, de forma alguma, aponta que um periódico anteriormente classificado como A Internacional passará a ser classificado como A1. É pertinente ressaltar, também, que cada área de avaliação apresenta uma equivalência exclusiva. No entanto, a que melhor se aplica à classificação anterior e vigente na área de avaliação Engenharias III pode ser observada no quadro 5:

Quadro 5 - Equivalência entre os Qualis 2004-2006 e 2007-2009 da área de avaliação Engenharias III

\begin{tabular}{|c|c|}
\hline QUALIS 2004-2006 & QUALIS 2007-2009 \\
\hline A1 & A Internacional \\
\hline A2 & B internacional \\
\hline B1 & A Nacional \\
\hline B2 & C Internacional \\
\hline B3 & B Nacional \\
\hline B4 & C Nacional \\
\hline B5 & A Local \\
\hline
\end{tabular}

Fonte: Autoria própria (2009)

Tal equivalência não pode ser aplicada em todas as áreas do conhecimento, tendo em vista que algumas áreas classificam os artigos de nível $\mathrm{C}$ Internacional como superiores aos artigos de nível A Nacional, o que não ocorre na Engenharias III. Outro indicativo é que os níveis de exigência foram ampliados. No modelo anterior, a produção qualificada era considerada a alocada nos níveis A e B Internacional e A Nacional. Na atual proposta, os níveis que não possuem saturação são A1, A2 e B1. Em termos práticos, os principais periódicos brasileiros da sub-área da Engenharia de Produção, a Revista Gestão \& Produção e a Revista Produção, antes alocados no nível A Nacional, foram classificados como B2. Objetivamente, as publicações em língua inglesa 
foram conformadas como a única possibilidade realmente adequada de publicação, o que determinará restrições aos periódicos nacionais. Certamente, o endereço dos resultados de pesquisas qualificadas produzidas na pós-graduação brasileira, mantida em parcela significativa com dinheiro público, não será o dos periódicos brasileiros. O estado da arte produz outros problemas que não serão discutidos por fugir do escopo da presente proposta.

A equivalência apresentada anteriormente diz respeito somente à equiparação de pesos entre ambos os Qualis. Com relação aos critérios de classificação, um comparativo entre a classificação do Qualsi 2004-2006 e a classificação previamente divulgada pela CAPES referente ao Qualis 2007-2009 está contida no quadro 6.

Quadro 6 - Comparativo entre os Qualis 2004-2006 e 2007-2009 da área de avaliação Engenharias III

\begin{tabular}{|c|c|c|}
\hline QUALIS & 2004-2006 & $2007-2009$ \\
\hline $\begin{array}{l}\text { A Internacional } \\
\text { (A1) }\end{array}$ & $\begin{array}{l}\text { Periódicos da área Engenharias III de } \\
\text { cunho científico e circulação } \\
\text { internacional com fatores de impacto } \\
\text { maiores ou iguais a } 0,3\end{array}$ & $\begin{array}{l}\text { Periódicos de qualquer das Engenharias com } \\
\text { fator de impacto superior a } 0,9 \text { ou periódicos } \\
\text { de outras áreas com } \mathrm{j}^{*} \text { superior a } 1,22\end{array}$ \\
\hline $\begin{array}{l}\text { B Internacional } \\
\text { (A2) }\end{array}$ & $\begin{array}{l}\text { Periódicos da área Engenharias III de } \\
\text { cunho científico e circulação } \\
\text { internacional com fator de impacto } \\
\text { menores que } 0,3 \text { e maiores do que } 0,01\end{array}$ & $\begin{array}{l}\text { Periódicos de qualquer das Engenharias com } \\
\text { fator de impacto superior a } 0,5 \text { e inferior a } 0,9 \\
\text { ou periódicos de outras áreas com } \mathrm{j}^{*} \text { superior } \\
\text { a } 1,06 \text { a inferior a } 1,22\end{array}$ \\
\hline A Nacional (B1) & $\begin{array}{l}\text { Periódicos de cunho científico com } \\
\text { ampla circulação nacional e com corpo } \\
\text { editorial predominantemente nacional, } \\
\text { que não possuem fator de impacto, } \\
\text { mas reconhecidos pela comunidade } \\
\text { científica como de excelência. } \\
\text { Periódicos Brasileiros incluídos no } \\
\text { SCIELO são considerados como NA. }\end{array}$ & $\begin{array}{l}\text { Periódicos de qualquer das Engenharias com } \\
\text { fator de impacto superior a } 0,3 \text { e inferior a } 0,5 \\
\text { ou periódicos de outras áreas com } \mathrm{j}^{*} \text { superior } \\
\text { a } 0,8 \text { a inferior a } 1,06 \text {. Periódicos de } \\
\text { circulação internacional, sem fator de } \\
\text { impacto, mas importantes para as áreas, com } \\
\text { índice de citações elevado. Periódicos que não } \\
\text { possuem fator de impacto e não são indexados } \\
\text { no Scielo, mas que constavam na classificação } \\
\text { do Qualis 2004-2006 como A Internacional }\end{array}$ \\
\hline $\begin{array}{l}\text { C Internacional } \\
\text { (B2) }\end{array}$ & $\begin{array}{l}\text { Periódicos de circulação internacional } \\
\text { em processo de reconhecimento pela } \\
\text { comunidade científica e que ainda não } \\
\text { apresentam índice de impacto }\end{array}$ & $\begin{array}{l}\text { Periódicos de qualquer das Engenharias com } \\
\text { fator de impacto superior a } 0,01 \text { e inferior a } \\
0,3 \text { ou periódicos de outras áreas com j* } \\
\text { superior a } 0,01 \text { a inferior a } 0,8 \text {. Periódicos de } \\
\text { circulação internacional, sem fator de } \\
\text { impacto, mas importantes para as áreas, com } \\
\text { índice de citações mediano. Os demais } \\
\text { periódicos indexados no Scielo (de qualquer } \\
\text { área). Periódicos da Engenharia que não } \\
\text { possuem fator de impacto e não são indexados } \\
\text { no Scielo, mas que constavam na classificação } \\
\text { do Qualis 2004-2006 como B Internacional }\end{array}$ \\
\hline B Nacional (B3) & $\begin{array}{l}\text { Periódicos de abrangência nacional, } \\
\text { com corpo } \\
\text { predominantemente nacional editorial } \\
\text { considerados pela comunidade } \\
\text { científica como de boa qualidade e boa } \\
\text { regularidade. }\end{array}$ & $\begin{array}{l}\text { Periódicos de áreas cujo fator Q é superior a } 6 . \\
\text { Periódicos de circulação internacional, sem } \\
\text { fator de impacto, mas importantes para as } \\
\text { áreas, com índice de citações baixo. } \\
\text { Periódicos da Engenharia que não possuem } \\
\text { fator de impacto e não são indexados no } \\
\text { Scielo, mas que constavam na classificação do } \\
\text { Qualis 2004-2006 como C Internacional. }\end{array}$ \\
\hline
\end{tabular}




\begin{tabular}{|l|l|l|}
\hline C Nacional (B4) & $\begin{array}{l}\text { Periódicos científicos de divulgação } \\
\text { com abrangência nacional. }\end{array}$ & $\begin{array}{l}\text { Periódicos cujo fator Q é superior a 3 e } \\
\text { inferior a 6. Periódicos da Engenharia que não } \\
\text { possuem fator de impacto e não são indexados } \\
\text { no Scielo, mas que constavam na classificação } \\
\text { do Qualis 2004-2006 como A Nacional. }\end{array}$ \\
\hline \multirow{2}{*}{ A Local (B5) } & $\begin{array}{l}\text { Periódicos cujo fator Q é inferior a 3. } \\
\text { Periódicos da Engenharia que não possuem } \\
\text { fator de impacto e não são indexados no } \\
\text { área Engenharias III. }\end{array}$ & $\begin{array}{l}\text { Scielo, mas que constavam na classificação do } \\
\text { Qualis 2004-2006 como B Nacional, C } \\
\text { Nacional ou A Local. Periódicos de circulação } \\
\text { local. }\end{array}$ \\
\hline
\end{tabular}

Fonte: Autoria própria (2009)

Alterações significativas são notáveis. O grande acréscimo de periódicos, que de início se demonstrava favorável à Engenharia de Produção, após o comparativo entre ambos os Qualis, demonstra que tal mudança não se apresenta tão promissora para a sub-área. Em contrapartida ao aumento do número de periódicos, o aumento nas exigências para o mais alto nível na classificação constitui um fator limitante na sub-área em exame.

No Qualis 2004-2006, os periódicos da grande área Engenharias classificados como A Internacional representavam 57,59\% do total de periódicos indexados no Qualis da referida área. A tabela 1 exibe o número de periódicos indexados ao Qualis 2004-2006 de cada área de avaliação da grande área Engenharias, seccionados por classificação:

Tabela 1 - Número de periódicos indexados no Qualis do triênio 2004-2006

\begin{tabular}{l|c|c|c|c|c}
\hline & Engenharias I & Engenharias II & Engenharias III & Engenharias IV & TOTAL \\
\hline A Internacional & 178 & 734 & 397 & 417 & 1726 \\
\hline B Internacional & 81 & 41 & 58 & 31 & 211 \\
\hline C Internacional & 8 & 147 & 59 & 85 & 299 \\
\hline A Nacional & 40 & 36 & 51 & 31 & 158 \\
\hline B Nacional & 56 & 85 & 38 & 8 & 187 \\
\hline C Nacional & 43 & 51 & 16 & 37 & 147 \\
\hline A Local & 50 & 34 & 114 & 2 & 200 \\
\hline B Local & 7 & 2 & 2 & 0 & 11 \\
\hline C Local & 42 & 6 & 1 & 9 & 58 \\
\hline
\end{tabular}

O número de periódicos classificados como A Internacional na área de avaliação Engenharias II apresenta um desequilíbrio entre as demais áreas de avaliação, possuindo 42,53\% do total de periódicos da grande área Engenharias cuja classificação no Qualis 2004-2006 é A Internacional. Em seguida, a área de avaliação Engenharias IV possui $24,16 \%$ do total de periódicos da grande área em exame. Ainda que esse percentual seja próximo da área de avaliação Engenharias III (23\%), é pertinente ressaltar que a Engenharias IV possui somente duas sub-áreas, enquanto a Engenharias III possui quatro sub-áreas. Dessa forma, o número de periódicos de cada sub-área da Engenharias IV é, em tese, superior ao número de periódicos de cada sub-área da Engenharias III. A área Engenharias I é, por sua vez, a que possui o menor número de periódicos $(10,31 \%)$. 
Frente aos indicadores obtidos na avaliação dos cursos de pós-graduação da CAPES no triênio 2004-2006, somados aos indicadores propostos no presente trabalho, a configuração dos programas avaliados é apresentada na tabela 2.

Tabela 2 - Dados do triênio 2004-2006 das sub-áreas da grande área Engenharias

\begin{tabular}{|c|c|c|c|c|c|c|}
\hline & & $\begin{array}{c}\text { Número de } \\
\text { programas } \\
\text { de pós- } \\
\text { graduação }\end{array}$ & $\begin{array}{l}\text { Percentual } \\
\text { de } \\
\text { doutorados }\end{array}$ & $\begin{array}{l}\text { Conceito } \\
\text { médio }\end{array}$ & $\begin{array}{c}\text { Total de } \\
\text { artigos A } \\
\text { Internacional }\end{array}$ & $\begin{array}{l}\text { Média } \\
\text { de } \\
\text { artigos }\end{array}$ \\
\hline \multirow{3}{*}{$\begin{array}{c}\text { Engenharias } \\
\text { I }\end{array}$} & Engenharia Civil & 37 & 0,43 & 3,97 & 438 & 12 \\
\hline & $\begin{array}{l}\text { Engenharia de } \\
\text { Transportes }\end{array}$ & 8 & 0,50 & 4,37 & 14 & 2 \\
\hline & Engenharia Sanitária & 22 & 0,41 & 3,95 & 154 & 7 \\
\hline \multirow{4}{*}{$\begin{array}{c}\text { Engenharias } \\
\text { II }\end{array}$} & $\begin{array}{l}\text { Engenharia de Materiais e } \\
\text { Metalúrgica }\end{array}$ & 28 & 0,75 & 4,50 & 2690 & 96 \\
\hline & Engenharia de Minas & 3 & 0,33 & 3,00 & 29 & 10 \\
\hline & Engenharia Nuclear & 7 & 0,57 & 4,14 & 790 & 113 \\
\hline & Engenharia Química & 30 & 0,47 & 3,97 & 1716 & 57 \\
\hline \multirow{4}{*}{$\begin{array}{c}\text { Engenharias } \\
\text { III }\end{array}$} & Engenharia Aeroespacial & 3 & 0,67 & 5,00 & 321 & 107 \\
\hline & Engenharia de Produção & 30 & 0,33 & 3,53 & 160 & 5 \\
\hline & Engenharia Mecânica & 35 & 0,66 & 4,03 & 865 & 25 \\
\hline & $\begin{array}{l}\text { Engenharia Naval e } \\
\text { Oceânica }\end{array}$ & 3 & 0,67 & 3,33 & 33 & 11 \\
\hline \multirow{2}{*}{$\begin{array}{c}\text { Engenharias } \\
\text { IV }\end{array}$} & Engenharia Biomédica & 5 & 0,60 & 4,80 & 246 & 49 \\
\hline & Engenharia Elétrica & 44 & 0,52 & 4,07 & 1594 & 36 \\
\hline
\end{tabular}

Como indicado na tabela 2, é perceptível que a média de artigos A Internacional é uma grandeza diretamente proporcional ao conceito médio, percentual de doutorados e número de periódicos da área de avaliação. Uma análise de correlação aponta que a média de artigos A Internacional publicados e o número de periódicos, percentual de doutorados e o conceito médio estão correlacionados em $0,573,0,593$ e 0,610 , respectivamente.

Tendo em vista que o valor crítico do coeficiente de correção de Pearson para uma população/amostra de 13 elementos é $0,553(\alpha=0,05)$, pode-se afirmar que todos os indicadores apresentam correlação significativa com a média de artigos A Internacional publicados. Analisando os indicadores da sub-área Engenharia de Produção, verifica-se que esta apresenta a pior média de artigos A Internacional publicados (5), o pior percentual de doutorados, juntamente com a sub-área Engenharia de Minas $(0,33)$ e o terceiro pior conceito médio $(3,53)$, a frente somente das sub-áreas Engenharia Naval e Oceânica (3,33) e Engenharia de Minas (3).

Ao sugerir a política de regras únicas para o Qualis das grandes áreas como Engenharias, Medicina e Biologia, o que não ocorreu, a CAPES atentou-se em recomendar que:

pelo menos no interior de cada Grande Área, se procure formular regras de Qualis próximas entre si, mas sem, de forma alguma, gerar depreciação das áreas que têm maior tradição de publicação em periódicos ou sobrevalorização daquelas que ainda têm pouco volume nesse 
campo; portanto, um periódico pode obter notas diferentes em distintas áreas (TOURINHO; BASTOS, 2008, p. 09).

Se fosse seguida a diretriz da unificação, a única alternativa para se ter um Qualis único sem depreciar áreas de maior tradição e nem sobrevalorizar periódicos de áreas de menor volume, seria desvalorizar os periódicos de áreas menos abastadas. Assim, para a Engenharia de Produção, os efeitos no Qualis 2007-2009 seriam:

- Aumento do número total de periódicos;

- Número total de periódicos nos dois primeiros extratos sem grande variação;

- $\quad$ Aumento do número total de periódicos no terceiro e quarto extrato;

- Número de periódicos específicos da sub-área da Engenharia de Produção sem grande variação;

- Número de periódicos específicos da sub-área da Engenharia de Produção nos dois primeiros extratos bastante reduzido;

- Número de periódicos específicos da sub-área da Engenharia de Produção no terceiro e quarto extrato é aumentado, em função da depreciação dos periódicos classificados anteriormente nos três primeiros extratos;

- Número de periódicos específicos da sub-área da Engenharia de Produção nos demais extratos sem grande variação.

Tal proposição anunciada não fora seguida pela CAPES, que, em março de 2009, publicou o Qualis 2007-2009 sem a unificação das áreas de avaliação da grande-área Engenharias. Os critérios utilizados para tal classificação ainda não foram divulgados. A classificação vigente do Qualis apresenta uma profunda variação no número de periódicos em cada extrato. O número de periódicos de cada área de avaliação da grande-área Engenharias, em secção por extrato, é demonstrado na tabela 3 .

Tabela 3 - Número de periódicos indexados no Qualis do triênio 2007-2009

\begin{tabular}{c|c|c|c|c|c}
\hline & Engenharias I & Engenharias II & Engenharias III & Engenharias IV & TOTAL \\
\hline A1 & 110 & 171 & 158 & 128 & 567 \\
\hline A2 & 125 & 200 & 166 & 131 & 622 \\
\hline B1 & 128 & 279 & 273 & 233 & 913 \\
\hline B2 & 43 & 269 & 48 & 169 & 529 \\
\hline B3 & 84 & 276 & 178 & 39 & 577 \\
\hline B4 & 148 & 89 & 178 & 63 & 478 \\
\hline B5 & 247 & 149 & 258 & 236 & 890 \\
\hline C & 0 & 0 & 30 & 21 & 51 \\
\hline
\end{tabular}

Frente à classificação publicada pela CAPES, os efeitos do Qualis 2007-2009 na área de avaliação Engenharias III são: 
- $\quad$ Aumento do número total de periódicos, de 736 para 1289;

- Número total de periódicos nos quatro primeiros extratos sem grande variação, de 565 para 645;

- Aumento do número de periódicos dos extratos subseqüentes, de 171 para 644;

- $\quad$ Decréscimo do número de periódicos no primeiro extrato, de 397 para 158;

- Aumento do número de periódicos no segundo, terceiro e quarto extrato, de 168 para 487, em função da depreciação de periódicos anteriormente alocados no primeiro extrato.

Ainda que a unificação do Qualis das Engenharias não tenha se materializado, conforme fora proposto pela CAPES, a nova classificação compatibiliza-se com alguns dos critérios anteriormente propostos, explicitados no quadro 3. Com efeito, percebe-se que os periódicos da Engenharias III que possuíssem fator de impacto entre 0,3 e 0,5 , anteriormente classificados no primeiro extrato (A Internacional), passariam a ser classificados somente no terceiro extrato (B1). Os periódicos que possuíam fator de impacto até 0,3 , anteriormente classificados no segundo extrato (B Internacional), passariam a ser classificados no quarto extrato (B2). A maioria dos periódicos classificados anteriormente no terceiro extrato (A Nacional) seriam alocados no quarto extrato (B2). Assim, o número de periódicos nacionais da Engenharia de Produção classificados no terceiro extrato do Qualis, que já era limitado, passaria a ser nulo. Na perspectiva apresentada, fica evidenciado que, em grande parte, tais predições se concretizaram. As vantagens da mudança do Qualis, se mostram bastante restritas para a Engenharia de Produção.

Mesmo sem a unificação do Qualis, a sugestão da CAPES de criar as mesmas regras para todas as áreas de avaliação da grande-área Engenharias também apresenta grandes fragilidades. Tal equidade seria justa somente se houvesse grande proximidade entre o número e nível dos periódicos de todas as áreas de avaliação. A CAPES ainda alerta sobre o cuidado ao elaborar uma regra única, para evitar a depreciação de periódicos impactantes ou a supervalorização de periódicos que não mereçam uma classificação superior. Como não há maneira de equiparar ambos os extremos, a alternativa restante foi não depreciar os periódicos impactantes no meio acadêmico, mas sim, depreciar os periódicos das sub-áreas cujo número de periódicos é reduzido. Assim, todas as exigências da CAPES foram devidamente seguidas.

\section{Considerações finais}

É visível que houve uma tentativa de tornar os estratos A1 e A2 como exclusividade de periódicos de excelência e com grande destaque sobre os demais extratos. Entretanto, o percentual de periódicos dos dois primeiros extratos do Qualis 2007-2009 se tornou muito reduzido em comparação ao percentual de periódicos dos dois primeiros extratos no Qualis 2004-2006. Estes 
extratos, que representavam $61,82 \%$ do total de periódicos da área de avaliação Engenharias III, passam agora a representar somente $25,13 \%$ do total de periódicos indexados no Qualis.

O número de periódicos das áreas de avaliação Engenharias I, II, III e IV editados no Brasil, anteriormente classificados como A Nacional, é drasticamente reduzido no extrato B1 do Qualis 2007-2009. Naturalmente, áreas com número restrito de periódicos, como a Engenharia de Produção, deixam de possuir periódicos nacionais classificados como B1.

A proposição de criação de um Qualis único para as áreas como Medicina I, II, III e IV, Ciências Biológicas I, II e III e Engenharias I, II, III e IV não fora seguida. Tal decisão é positiva para as sub-áreas da grande-área Engenharias, tendo em vista que há uma grande disparidade existente entre estas. Dificilmente um artigo proveniente da Engenharia Biomédica teria inserção em periódicos da Engenharia Mecânica ou Engenharia Naval e Oceânica. Diversos outros exemplos com esse mesmo caráter podem ser formulados. Com relação à Engenharia de Produção, cabe ressaltar que artigos advindos de diferentes sub-áreas da Engenharias possuem compatibilidade com o escopo da Engenharia de Produção. No entanto, o reverso se faz presente em uma escala bastante reduzida.

Mesmo sem a unificação do Qualis das áreas Engenharias, a Engenharia de Produção fora fortemente lesada com o novo Qualis. O aumento do número de periódicos indexados no Qualis não representa uma melhoria significativa à área, ao passo que grande parte dos periódicos adicionais não apresenta escopo compatível ou a compatibilidade é bastante limitada com as linhas de pesquisa da Engenharia de Produção. As elevadas exigências para classificação nos dois primeiros extratos causou, em grande escala, uma depreciação de periódicos da Engenharias III.

Estas alterações constituem um fator bastante negativo à área objeto de estudo deste trabalho, e, trazem consigo, um grande desafio aos programas de pós-graduação em Engenharia de Produção para o triênio vigente, que foi iniciado, e está terminando, de forma obscura: o Qualis do ano-base 2007 foi disponibilizado durante poucos dias no final de dezembro de 2008, ficando indisponível até o início de março de 2009.

No dia 05 de março de 2009, a CAPES publicou o Qualis ano-base 2007. Entretanto, as quatro áreas de avaliação da grande-área Engenharias apresentaram classificações diferenciadas, contrastando com as regras anunciadas para o novo Qualis das Engenharias. Sobretudo, o Qualis publicado não condiz com o que fora proposto no Quadro 3, que, até última instância, deveria constituir os critérios para a composição do Qualis vigente das áreas de avaliação da Engenharias. Ainda que o projetado não tenha se concretizado por completo, a sub-área Engenharia de Produção prevalece bastante lesada com a classificação em vigor. Os critérios utilizados para a confecção de tal classificação permanecem desconhecidos. 
Com a mutabilidade quase que anual do Qualis e a demora para que periódicos mais qualificados publiquem os artigos aprovados, o cenário é absolutamente sombrio. Mais grave ainda, é que, de maneira idêntica ao ocorrido com o Qualis, os documentos de área relativos ao triênio 2007-2009, não foram divulgados, mesmo com o triênio praticamente concluído. Em termos práticos, está se jogando um jogo sem regras. Mesmo quando as regras são “conhecidas”, o cenário caliginoso não se desfaz. O que foi amplamente divulgado não passou de um devaneio.

\begin{abstract}
This study objectifies to analyze the effects of Qualis 2007-2009 on the evaluation of bibliographic production quality of the graduation programs of Production Engineering sub area. Basis on the data of the triennial evaluation of 2004-2006 of CAPES and of the information of Qualis 2004-2006 and 2007-2009, both Qualis was analyzed and the main alterations on the new Qualis was highlighted. It was verified that the unification proposal of Qualis in the great area Engineering, announced by CAPES, was not formalized. From the classification published by CAPES, whose criteria remain unknown, there was an increase of numbers of periodicals indexed to Qualis; Besides the number of periodicals increase, the additional periodicals concentrates on Qualis' inferior extracts; The exigency for classification in the two Qualis' superior extracts were increased; The periodicals published in Brazil were depreciated and; The Production Engineering sub area had a drastic reduction of number of periodicals classified in Qualis' superior extracts. It concludes that the new classification of the Qualis foments a very challenging triennium to the graduation programs of the sub area boarded on this paper.
\end{abstract}

Key-words: Qualis, Production Engineering, periodicals, bibliographic production, graduation.

\title{
Referências
}

COORDENAÇÃO DE APERFEIÇOAMENTO DE PESSOAL DE NÍVEL SUPERIOR - CAPES. Coordenação de Aperfeiçoamento de Pessoal de Nível Superior. Disponível em: <http://ww.capes.gov.br>. Acesso em 25 jan. 2008.

COORDENAÇÃO DE APERFEIÇOAMENTO DE PESSOAL DE NÍVEL SUPERIOR - CAPES. Perguntas mais freqüentes - Qualis. 2007a.

COORDENAÇÃO DE APERFEIÇOAMENTO DE PESSOAL DE NÍVEL SUPERIOR - CAPES. Principais características do Qualis. 2007b.

SAMPAIO, C. H.; SOUZA, S. M. A. G. U. de. Reunião com os coordenadores de pós-graduação da área de Engenharias II. Campina Grande, 11-12 ago. 2008.

TOURINHO, E. Z.; BASTOS, A. V. B. Qualis de periódicos 2008. In: SIMPÓSIO DA ANPEPP, 12., 2008, Natal. Anais... Natal: ANPEPP, 2008.

\section{Dados dos (as) autores (as)}

Nome completo: Bruno Pedroso

Filiação institucional: Universidade Tecnológica Federal do Paraná (UTFPR)

Departamento: Gerência de Pesquisa e Pós-Graduação 
Função ou cargo ocupado: Mestrando em Engenharia de Produção - bolsista da CAPES

Endereço completo para correspondência (bairro, cidade, estado, país e CEP): Av. Monteiro Lobato, Km 04, s/n, CEP: 84016-210, Ponta Grossa - PR - Brasil

Telefones para contato: (42) 32204875

e-mail:brunops3@brturbo.com.br

Nome completo: Luiz Alberto Pilatti

Filiação institucional: Universidade Tecnológica Federal do Paraná (UTFPR)

Departamento: Gerência de Pesquisa e Pós-Graduação

Função ou cargo ocupado: Professor do Programa de Pós-Graduação em Engenharia de Produção

Endereço completo para correspondência (bairro, cidade, estado, país e CEP): Av. Monteiro

Lobato, Km 04, s/n, CEP: 84016-210, Ponta Grossa - PR - Brasil

Telefones para contato: (42) 32204875

e-mail:lapilatti@utfpr.edu.br

Recebido para publicação em: 17/03/2009

Aceito para publicação em: 08/06/2009 